\title{
Effect of Cigarette Smoke Exposure on Maturation of the Antibody Response in Spleens of Newborn Mice
}

\author{
HERBERT B. HERSCOWITZ AND RUTH B. COOPER \\ Department of Microbiology, Georgetown University, Schools of Medicine and Dentistry, Washington, D. C. USA
}

\begin{abstract}
Summary
Balb/c mice were exposed to smoke from Kentucky Reference IRI cigarettes within $24 \mathrm{hr}$ after birth on a Prototype Mark II Walton Horizontal Smoke Exposure Machine for various periods of time up to 10 wk of age. There was no difference in the magnitude of the splenic plaque-forming cells (PFC) response in smoke-exposed and untreated control animals immunized with sheep red blood cells (SRBC) on sequential days up to day 9 postpartum. However, beginning at day 10 and for each subsequent time period assayed thereafter, there was a statistically significant reduction in the number of splenic PFC observed in the smokeexposed animals. On day 10, the PFC response of smoke-exposed mice was reduced by $33 \%$, on day 14 , there was a $60 \%$ reduction, whereas animals exposed to smoke from 4-10 wk showed a $90 \%$ reduction of the splenic PFC response.
\end{abstract}

\section{Speculation}

The finding that exposure of newborn mice to cigarette smoke resulted in a marked inhibition of the maturation of the splenic antibody response to $\mathrm{SRBC}$ is consistent with previous reports of the immunosuppressive effects of cigarette smoke exposure in experimental animals and humans. It is possible that this inhibitory effect is manifest at the level of the macrophage or the thymusderived lymphocyte, both of which have been suggested to be functionally immature in the newborn mouse.

The immune response to many, if not most, immunogens appears to involve a complex series of interactions among three heterogeneous functional cell types: bone marrow-derived lymphocytes (B cells), thymus-derived lymphocytes ( $T$ cells), and macrophages. It is now well accepted that the ability to respond immunologically to challenge with foreign materials undergoes a process of maturation that begins during embryonic development (21). Whereas it has been suggested that most cases of immunologic immaturity in neonatal animals or immunologic deficiency in adults can be attributed to the absence or a functional abnormality in immunocompetent $B$ and/or $T$ lymphocytes, there is also evidence to suggest that immaturity or defects in macrophage function can account for a lack of immune responsiveness $(1,7)$.

Exposure of experimental animals and humans to cigarette smoke has been shown to have profound effects on immune responsiveness (13). It has been amply demonstrated that both humoral and cell-mediated immune responses can be depressed as a consequence of smoke exposure, either in vivo or in vitro (4, $5,11,23,24)$. Whereas the precise mechanism involved in the immunosuppression induced by cigarette smoke exposure remains unclear, both macrophages (8) and antibody-producing cells (22) have been shown to be affected.

A summary of epidemiologic studies directed toward establishing a possible causal relationship between maternal cigarette smoking and congenital defects, which appeared in the 1973 report of the United States Department of Health, Education and Welfare (25), indicated that no definitive conclusions could be drawn at that time. Rickzeh et al. (17) found that exposure of female rats to high doses of cigarette smoke during gestation did not result in significant differences in regard to litter weight, litter size, number of implantation sites, the incidence of resorptions, or in the appearance of skeletal abnormalities when compared to untreated controls, thereby supporting the previously mentioned report. Interestingly, in a study of sera obtained at delivery from a large number of pregnant women, Nymand (15) found a significantly lower incidence of lymphocytotoxic antibodies in women who smoked compared to a matched control group of nonsmokers. In addition, the smokers had a higher incidence of urinary tract infections as well as febrile and nonfebrile virus diseases during pregnancy than did nonsmokers. Unfortunately, no mention was made of the physiologic or immunologic status of the offspring in the above study nor is any information available regarding the effect of cigarette smoke on the maturation of the immune response.

The purpose of the present study was to determine what effect, if any, smoke exposure of neonatal animals would have on the maturation of immune responsiveness as measured by the appearance of splenic PFC's.

\section{MATERIALS AND METHODS}

\section{ANIMALS}

Balb/c mice were purchased from Laboratory Supply Co., Indianapolis, IN for purposes of establishing a breeding colony in this department. Three females were added to a cage that already contained one male to establish a "breeding unit." After parturition, the neonatal animals were allowed to remain in the cage with the breeding unit until they were weaned at 17-18 days. On occasion, the cages contained as many as three litters, however, the deliveries were usually staggered so that animals of different ages could be readily identified. Upon weaning, the young mice were identified as belonging to a given litter and were housed 1620 per cage. Breeding units were kept intact during the course of this study. The animals were fed Purina Chow and given water ad libitum. The colony was routinely checked and found to be negative for antibody titers against common murine viruses which might have an influence on immune responsiveness by Microbiological Associates, Bethesda, MD.

\section{ANTIGEN AND IMMUNIZATION}

SRBC, in Alsever's solution, were obtained from Microbiological Associates, Bethesda, MD. The RBC from the same sheep were used throughout the course of this study. The SRBC were washed 4-6 times with phosphate buffered saline, pH 7.2 (PBS) before use. The packed cells were adjusted to a $25 \%$ (V/V) suspension with PBS. Animals up to 4 wk of age were injected with $0.05 \mathrm{ml}$ of the $25 \%$ suspension by the ip route using a 30 
gauge needle. Beyond the age of $4 \mathrm{wk}$, the animals were injected with $0.1 \mathrm{ml}$ of a $12.5 \%$ suspension of SRBC.

\section{ASSAY OF ANTIBODY-FORMING CELLS}

Four days after immunization, the mice were killed by cervical dislocation, and the number of antibody-forming cells in their spleens was determined by a modification of the liquid monolayer method described by Cunningham and Szenberg (3). Briefly, a reaction mixture containing the following reagents was prepared in $12 \times 75 \mathrm{~mm}$ glass tubes at room temperature: $0.2 \mathrm{ml}$ of a $10 \%$ suspension of thrice washed SRBC, $0.1 \mathrm{ml}$ of spleen cells (containing between $1-30 \times 10^{5}$ cells), $0.1 \mathrm{ml}$ of undiluted guinea pig complement (Baltimore Biological Laboratories, Cockeysville, MD) and $0.6 \mathrm{ml}$ of Minimal Essential Medium, Eagle's (Grand Island Biological Co., Grand Island, NY). A monolayer was formed by adding a measured amount $(0.02-0.04 \mathrm{ml})$ of the reaction mixture to each of three chambers formed by placing glass coverslips over double-sided tape on a standard glass microscope slide. After sealing the two open edges of each chamber with melted paraffin, the slides were incubated for $1 \mathrm{hr}$ at $37^{\circ} \mathrm{C}$ in an atmosphere of $5 \% \mathrm{CO}_{2}$ in air. PFC were enumerated macroscopically and verified under $32 \mathrm{X}$ magnification for the presence of a lymphoid cell in the center of the plaque. Results are expressed as the mean number of PFC $\pm \mathrm{SEM} / 10^{6}$ spleen cells. Each point represents an average of 10 animals. Each assay was carried out in triplicate on duplicate slides and was repeated on at least two separate occasions. The Student's $t$ test was used for comparing paired data. A probability level lower than 0.01 was regarded as significant.

\section{EXPOSURE TO CIGARETTE SMOKE}

Mice were exposed to smoke from standard Kentucky Reference IRI Cigarettes (KR IRI) obtained from the Tobacco-Health Research Institute, University of Kentucky, Lexington, KY on a Modified Walton Mark II Prototype Horizontal Smoke Machine supplied by the Council for Tobacco Research-U.S.A., Inc., New York as previously described (11). Briefly, 10 mice were placed in each of two plexiglass cone holders so that their snouts were protruding from the tapered ends of the cones. The animals were held in place by foam plugs so that they could not withdraw their noses from the open end of the cone. The plexiglass holders were then placed on either side of a hollow ring on the Walton machine, thereby forming a chamber for smoke exposure. The machine was adjusted to deliver an average puff volume of $35 \mathrm{ml}$ resulting in a 1:11 dilution of smoke in air when using a single cigarette. The exposure cycle consisted of a puff duration of $2 \mathrm{sec}$ in which smoke was forced into the exposure chamber, an inhalation period of $28 \mathrm{sec}$ in which smoke was mixed with air by means of a fan in the chamber and a $30 \mathrm{sec}$ purge with 2.5 liters of fresh air. The animals were exposed to smoke from the first 8 puffs of 2 KR IRI cigarettes once daily for the indicated times.

Smoke exposure was initiated within $24 \mathrm{hr}$ of birth. During exposure of animals under 10 days of age to the cigarette smoke, they were warmed gently by heat from a hair dryer so that the hairless animals would not be subjected to drafts while being handled on the machine. Such treatment resulted in minimal mortality of the animals.

Suckling animals were returned to their cages and were readily accepted by their mothers after smoke exposure. Mortality in smoke-exposed animals was less than $1 \%$ throughout the course of this study.

The experimental design utilized three groups of animals. Group 1 consisted of 175 animals exposed to cigarette smoke as described above for periods up to 10 wk. Group 2 consisted of an age-matched group of 145 animals which were subjected to the manipulation of being placed on the smoke exposure machine, but who were exposed to air rather than cigarette smoke for the same period of time. This group comprised the sham-controls. Group 3 consisted of 180 animals which were maintained in the same animal quarters, but which were not subjected to any of the potentially stressful conditions associated with the smoke exposure machine. This group comprised the untreated bench controls.

\section{RESULTS}

In order to ultimately evaluate the effect of cigarette smoke exposure on the maturation of the immune response in neonatal animals, initial experiments were carried out to determine the natural development of the PFC response in the spleens of growing Balb/c mice. Figure 1 shows that animals immunized within the first 6 days of life were incapable of mounting a statistically significant PFC response (maximum response of $24 \mathrm{PFC} / 10^{6}$ on day 6). Although not shown, the unimmunized control groups had a mean response of $20 \pm 14 \mathrm{PFC} / 10^{6}$ spleen cells. It should be noted that a significant number of plaques began to appear only after the lst wk of life. The number of PFC continued to increase slowly and then began to double after day 9 . The PFC response in the group of immunized animals exposed to smoke from two KR IRI cigarettes once daily beginning on the lst day of life and continuing through day 9 , was essentially the same as that of the normal, unexposed animals. In contrast, the PFC response of the animals exposed to the same amount of cigarette smoke for periods beyond 9 days was lower than that of the normal, untreated animals. By day 10 , there was a significant difference in the two groups; the untreated animals showed a mean response of 205 $\mathrm{PFC} / 10^{6}$ cells whereas those that were exposed to smoke had 73 PFC $/ 10^{6}$ cells, a $33 \%$ inhibition $(P<0.01)$. Although the splenic $P F C$ response continued to increase in the smoke-exposed group of animals, it did so at a lower rate so that by day 14, this group showed a $60 \%$ inhibition of the PFC response compared to the untreated control animals $(P<0.01)$.

Figure 2 shows a continuing maturation of the appearance of splenic PFC in normal Balb/c mice when assayed at biweekly intervals for a period up to $10 \mathrm{wk}$. It should be noted that there was a 3-fold increase in splenic PFC between 2 and 4 wk of age in response to immunization with SRBC. The splenic PFC response of normal animals continued to rise only slightly until 6 wk of age when it plateaued, having attained adult levels ( $10 \mathrm{wk}$ ). For each time period examined, beginning at $2 \mathrm{wk}$ of age, litters of mice were divided into two groups. One was used for exposure to cigarette smoke, whereas the other group from the same litter served as the sham control. The animals were exposed to smoke from two KR IRI cigarettes once each day for varying periods of time beginning within the first $24 \mathrm{hr}$ after birth. The animals were injected with SRBC at the appropriate time intervals and smoke exposure was continued for 4 days at which time their spleens were removed for the PFC assay. Note that the sham-exposed animals gave PFC responses which were essentially equivalent to the untreated control group $(P>0.05)$. However, the mean PFC response of this group was approximately $15-20 \%$ lower than the normal control. As previously observed, the PFC response of the smoke-exposed animals continued to increase over the course of this study. However, the response of the smoke-exposed animals was reduced by greater than $90 \%$ compared to that of either the sham-exposed or untreated control animals $(P<0.005)$.

\section{DISCUSSION}

The purpose of this study was to determine if exposure of neonatal animals to cigarette smoke would have an effect on the appearance of PFC in the spleens of neonatal mice. In order to determine this, it was first deemed necessary to follow the maturation of the splenic PFC response in normal Balb/c mice. The results (Fig. 1) indicated that significant numbers of splenic PFC appeared when animals were immunized between 7 and 14 days of age. These results are consistent with previous reports of the maturation of the early PFC response to SRBC in Balb/c mice $(2,16)$. There was an almost 3 -fold increase in the number of splenic PFC in animals immunized between 2 and 4 wk of age. A rapid increase of similar magnitude was reported by Spear et al. 


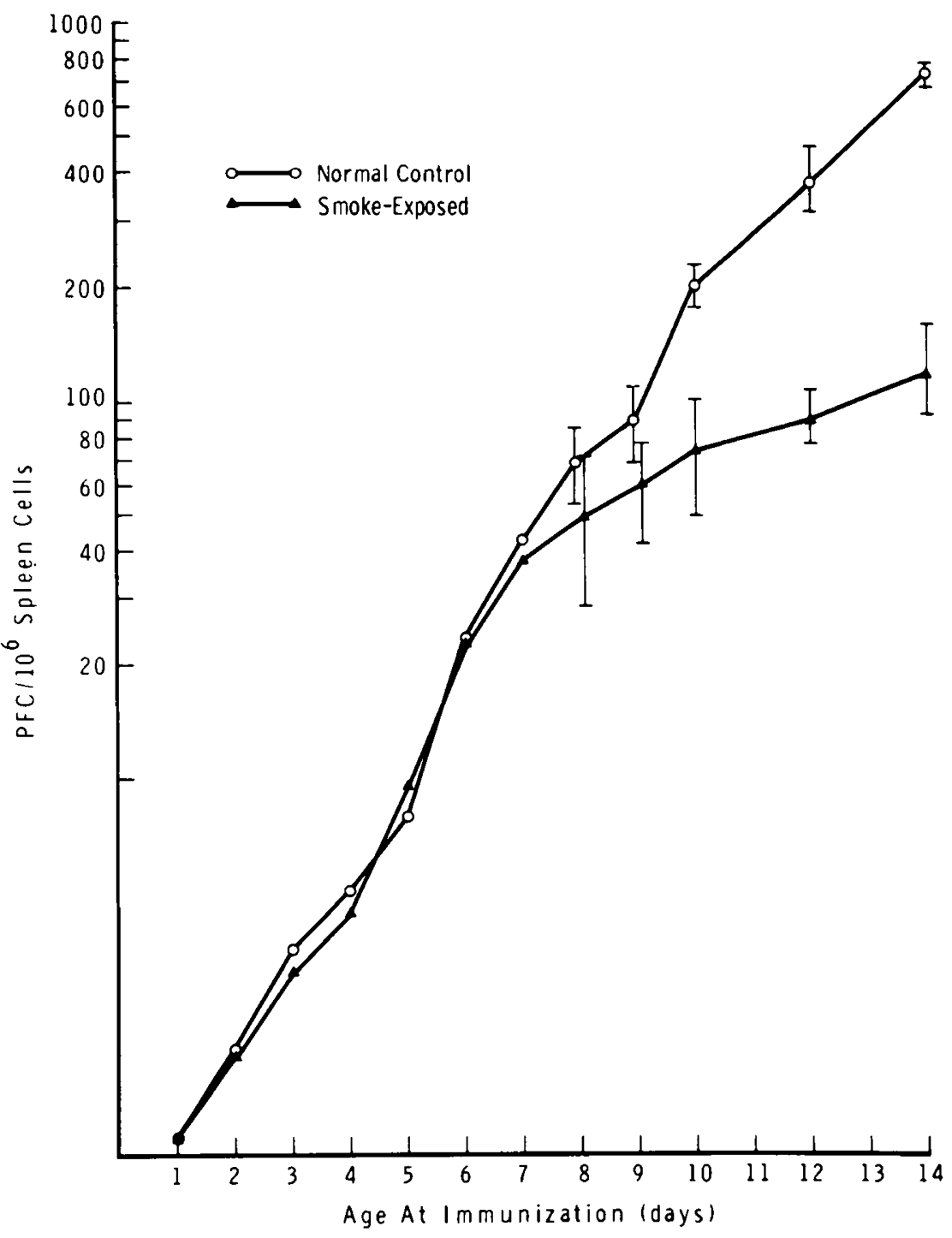

Fig. 1. Effect of cigarette smoke exposure on the early stages (days 1-14) of maturation of splenic plaque-forming cells in neonatal Balb/c mice. Animals were immunized with SRBC on the indicated days and spleens were assayed 4 days later.

(20) for the response to SRBC in the spleens of Swiss-L mice. There was only a slight further increase in the number of PFC in the spleen of 6-wk-old animals and this level remained relatively constant through $10 \mathrm{wk}$ of age.

When animals were exposed to cigarette smoke for various periods of time beginning within $24 \mathrm{hr}$ of birth there was no apparent difference in their ability to mount a splenic PFC response to SRBC up until day 9 of development (Fig. 1). However, beginning at day 10 and for each subsequent period assayed thereafter, there was a statistically significant reduction in the number of splenic PFC observed in the smoke-exposed animals. On day 10, the PFC response to smoke-exposed animals was $33 \%$ lower than controls, whereas on day 14 , there was a $60 \%$ reduction in the number of splenic PFC (Fig. 1). Animals which were immunized at intervals from 2-10 wk of age and exposed to cigarette smoke showed splenic PFC responses that were reduced by $90 \%$ compared to the untreated controls (Fig. 2).

The somewhat lower response observed in sham-exposed animals could possibly be explained by the stress conditions created by placing the animals in the confines of the smoke-exposure chambers. The authors have previously observed that adult shamexposed animals had decreased immune responses (11). This depression determined not to be statistically significant, never exceeded 10-20\% of the response of the untreated control animals in any of the studies that were carried out and, therefore, was not shown in Figure 1.

Spear et al. (20) have shown that immunoglobulin-bearing (B cells), theta-bearing ( $T$ cells) and specific antigen-binding cells appear in the spleens of mice at about 15-16 days of gestation. The number of these cells increases at a high rate during the interval before birth (19-20 days), continues to increase immediately after birth, and remains relatively constant from $1-2$ wk after birth. However, they also observed that consistent splenic PFC responses to specific antigens were not detected until animals were at least $2 \mathrm{wk}$ of age. Their results suggest that in spite of the fact that the animals can express a large variety of antigen-binding specificities before birth, maturational changes are required before the response to a given antigen can be manifest. Further, they suggested that it is likely that the changes that occur after birth are qualitative in nature because it was shown that there are similar relative proportions of the appropriate antigen-binding lymphocytes in fetal, neonatal, and adult spleen cell populations (20).

Argyris (1) and Bendinelli et al. (2) have suggested that the immunologic immaturity of newborn mice is not due to a defect in immunocompetent lymphocytes, but could be attributed to the immaturity of antigen-recognizing or antigen-processing cells, namely macrophages. In those studies, the transfer of syngeneic 


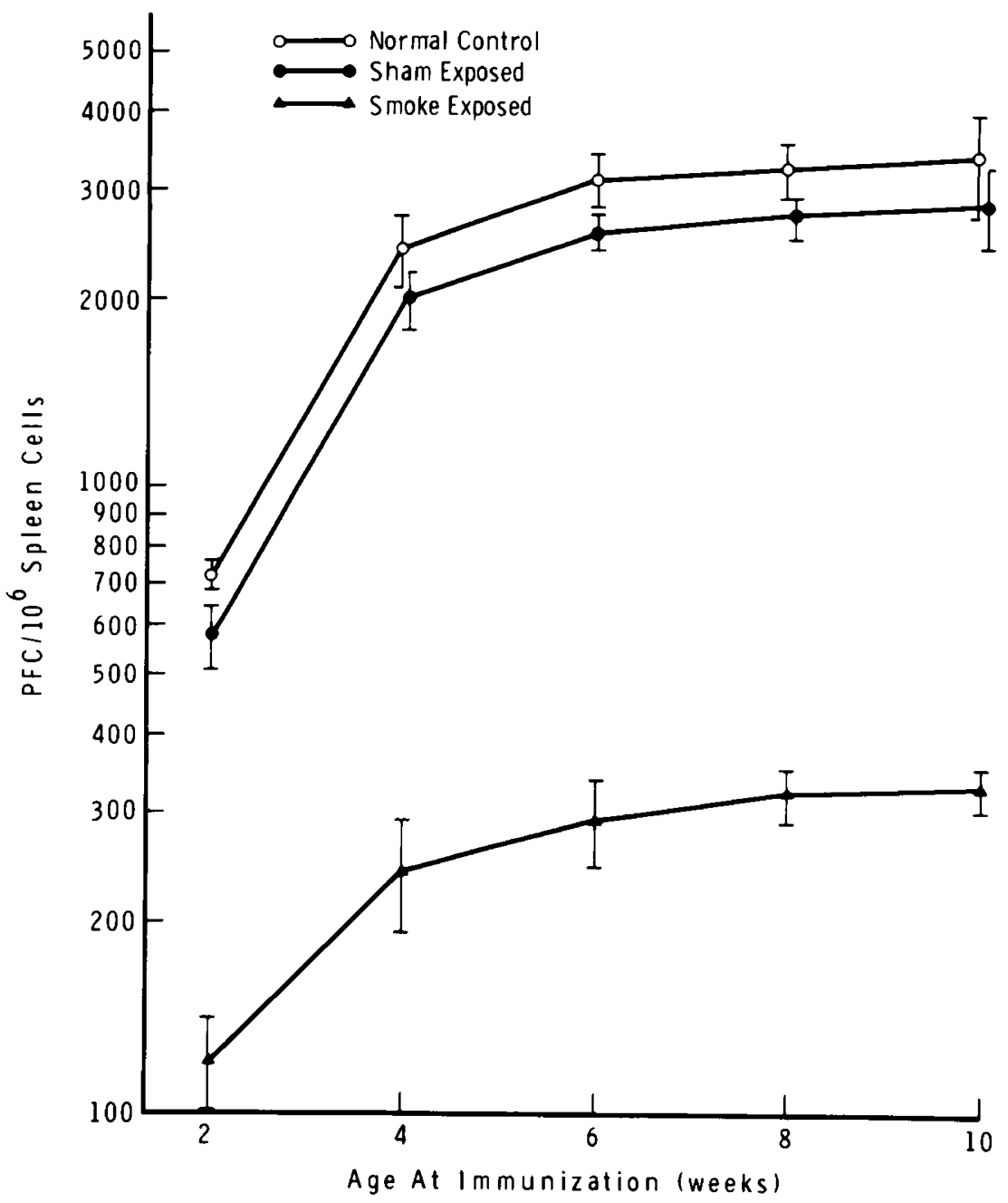

Fig. 2. Effect of cigarette smoke exposure on the maturation of the splenic plaque-forming response in Balb/c mice aged 2-10 wk. Assays were carried out 4 days after immunization.

adult peritoneal macrophages endowed normally unresponsive neonatal animals with the ability to manifest a splenic PFC response against $\mathbf{R B C}$. It was observed that there was a critical period (at about 3 days of age) in the development of the animal during which the spleen cells could benefit from the addition of adult macrophages (1). Similarly, a lack of functional macrophages in neonatal mice was suggested by Hardy et al. (9) based on studies in which peritoneal exudate cells from newborn mice were injected into sublethally irradiated adults. The recipient animals did not respond to Shigella antigen upon immunization However, if the mice were injected with macrophages from adul animals, an antibody response was observed. Mosier and Johnson (14) argued that immunologic immaturity of newborn animals could not be explained by the immaturity of macrophages because adherent cells taken from 2-wk-old mice could reconstitute the PFC response of unreactive nonadherent lymphocytes obtained from 8-wk-old mice. However, Argyris (1) showed that addition of adult macrophages to animals beyond the critical stage ( 3 days) had no effect. Thus, it is possible that the 2-wk-old macrophages used in Mosier's study were functionally mature. Mosier and Johnson (14) also showed that B cells were functionally mature in very young mice because a response to DNP-Ficoll, a T-independent antigen, was observed in lymphoid cell cultures obtained from 2-wk-old mice. Based on additional studies, they concluded that the inability of animals to respond to $T$-dependent antigens during the first few wk of life was due to the presence of an increased number of suppressor $T$ cells. On the other hand, the studies of Friedman et al. (6) and Hardy et al. (10) suggested that the underlying explanation for the delay in appearance of the immune response to $\mathrm{T}$-dependent antigens could be explained by a functional immaturity of $T$ cells. Finally, in a recent report Russell and Bolub (19) have suggested that the spleen provides an environmental influence on the maturation of thymus-derived lymphocytes that cooperate with B cells. Thus, removal of the spleen within the first $72 \mathrm{hr}$ of life results in an $80 \%$ reduction of normal B-T cooperative events in lymphoid cell populations. Splenectomy after this critical period ( 3 days) results in normal levels of B-T cooperation in an adoptive transfer system.

In a recent comprehensive review, Holt and Keast (13) presented evidence to indicate that exposure to cigarette smoke has a depressive effect on the immune response. Indeed, there is evidence to show that macrophages $(8,12)$ as well as $B$ and $T$ cells $(18)$ can be affected. It is, therefore, not surprising to observe that the maturation of the splenic PFC response in developing mice which are exposed to cigarette smoke is significantly inhibited. Whereas it is not possible to determine from the present study at which level this suppression is manifest, several alternatives can be advanced. First, it is possible that exposure to cigarette smoke interferes with the maturation of $\mathrm{T}$ lymphocytes in the spleen. Second, because macrophages have been shown to be affected by cigarette smoke, the defect could be at the level of this cell. Finally, and least likely in view of the work of others $(13,14,20)$, the defect could be manifest at the level of the B cell.

\section{REFERENCES AND NOTES}

I. Argyris, B. F.: Role of macrophages in immunological maturation. J. Exptl. Med., 128: 459 (1968).

2. Bendinelli, M., Sensi, S., and Falcone, G.: Effect of adult peritoneal cells on the 
antibody response of newborn mice to sheep red blood cells. J. Immunol., 106 : 1681 (1971).

3. Cunningham, A. J., and Szenberg, A.: Further improvements in the plaque technique for detecting single antibody forming-cells. Immunology, 14: 599 (1968).

4. Desplaces, A. Charreire, J., and Izard, C.: Action de la phase gazeuse de fumee de cigarette sur la transformation lymphoblastique du petit lymphocyte humain. Rev. Eur. Etud. Clin. Biol., 16: 822 (1971).

5. Finklea, J., Hasselblad, V., Reggan, W., Nelson, W., Hammer, D., and Newill, V.: Cigarette smoking and haemagglutination inhibition response to influenza after natural disease and immunization. Amer. Rev. Resp. Dis., 104: 368 (1971).

6. Friedman, D., Hardy, B., Danon, D., and Globerson, A.: Immunological status of the newborn mouse spleen. Israel J. Med. Sci., 10: 1179 (1974).

7. Gallily, R., and Feldman, M.: The role of macrophages in the induction of antibody in X-irradiated animals. Immunology, 12: 197 (1967).

8. Green, G., and Carolin, D.: The depressant effect of cigarette smoke on the in vitro antibacterial activity of alveolar macrophages. N. Engl. J. Med., 276: 421 (1967).

9. Hardy, B., Globerson, A., and Danon, D.: Ontogenic development of the reactivity of macrophages to antigenic stimulation. Cell. Immunol., 9: 282 (1973).

10. Hardy, B., Mozes, E., and Danon, D.: Comparison of the immune response potential of newborn mice to T-dependent and T-independent synthetic polypeptides. Immunology, 30: 261 (1976).

11. Herscowitz, H. B.: Effect of exposure to cigarette smoke on in vivo and in vitro immune responsiveness of Balb/c mice. In: Pulmonary Diseases: Defense Mechanisms and Populations at Risk. (University of Kentucky Press, Lexington, KY, 2: 250 (1977)

12. Holt, P. G., and Keast. D.: Acute effects of cigarette smoke on murine macrophages. Arch. Environ. Health, 26: 300 (1973).

13. Holt, P. G., and Keast, D.: Environmentally induced changes in immunologica function: acute and chronic effects of inhalation of tobacco smoke and othe atmospheric contaminants in man and experimental animals. Bact. Rev., 41 : 205 (1977)

14. Mosier, D. E., and Johnson. B. M.: Ontogeny of mouse lymphocyte function. II
Development of the ability to produce antibody is modulated by $T$ lymphocytes. J. Exptl. Med., 141: 216 (1975).

15. Nymand, G.: Maternal smoking and immunity. The Lancet, 2: 1379 (1974).

16. Playfair, J. H.: Strain differences in the immune response of mice. 1 . The neonatal response to sheep red cells. Immunology, 15: 35 (1968).

17. Rickzeh, G., Dontenwill, W., and Leuschner, F.: Testing of cigarette smoke inhalation for teratogenicity in rats. Toxicology, 4: 289 (1975).

18. Roszman, T. L., Elliott, L. H., and Rogers, A. S.: Suppression of lymphocyte function by products derived from cigarette smoke. Amer. Rev. Resp. Dis., III: 453 (1975).

19. Russell, J. L., and Golub, E. S.: Functional development of the interacting cells in the immune response. III. Role of the neonatal spleen. Eur. J. Immunol., 7: 305 (1977).

20. Spear, P. G., Wang, A. L., Rutishauser, U., and Edelman, G. M.: Characterization of splenic lymphoid cells in fetal and newborn mice. J. Exptl. Med., 138: 557 (1973).

21. Sterzl, J., and Silverstein, A. M.: Developmental aspects of immunity. Adv. Immunol., 6: 337 (1967).

22. Thomas, W. R., Holt, P. G., and Keast, D.: Antibody production in mice chronically exposed to fresh cigarette smoke. Experientia, 30: 1469 (1974).

23. Thomas, W. R., Holt, P. G., and Keast, D.: Cellular immunity in mice chronically exposed to fresh cigarette smoke. Arch. Environ. Health, 27: 372 (1973).

24. Thomas, W. R., Holt, P. G., and Keast, D.: Humoral immune response of mice chronically exposed to fresh cigarette smoke. Arch. Environ. Health, 30: 78 (1975).

25. United States Department of Health, Education and Welfare: The health consequences of smoking. DHEW Publication (HSM) 73-8704 (1973).

26. The authors thank Janet Phoenix Dixon for her secretarial assistance.

27. This research was supported by a grant from the Council for Tobacco ResearchU.S.A., Inc.

28. Requests for reprints should be addressed to: Dr. H. B. Herscowitz, Department of Microbiology, Georgetown University, Schools of Medicine and Dentistry, Washington, D. C. 20007 USA.

29. Received for publication May 26, 1978.

30. Accepted for publication June 7, 1978. 